\title{
REVISITANDO UM VELHO TEMA: SOBREPOSIÇÃO DE VOZES NO DIÁLOGO
}

REVISITING AN OLD THEME: VOICE OVERLAPPING IN DIALOGUE

\section{Luiz Antônio da Silva}

Universidade de São Paulo (Brasil)

Resumen

Neste trabalho, buscou-se focalizar a interação entre falante e ouvinte e, especialmente, os momentos em que se dá a violação da regra geral da conversação, "fala um de cada vez". O foco deste trabalho foi o fenômeno da sobreposição de vozes e, como foi esclarecido, não houve qualquer preocupação em definir e analisar a sobreposição do ponto de vista das estratégias de gestão de turnos, isto é, se houve ou não interrupção ou assalto ao turno, mas tão somente algumas razões que levam o interlocutor a sobrepor-se à fala daquele que está com a palavra.

PALABRAS CLAVE: vozes, diálogo, conversação
Abstract

In this paper, we sought to focus on the interaction between speaker and listener, and especially the moments in which the general rule of conversation occurs, "speak one at a time." The focus of this work was the phenomenon of voice overlap and, as has been clarified, there was no concern in defining and analyzing overlap from the point of view of shift management strategies, ie whether there was interruption or assault on the shift. but only a few reasons that lead the speaker to override the speech of the speaker.

KEY WORDS: voices, dialogue, conversation 


\section{CONSIDERAÇÕES INICIAIS}

Entre setembro de 2001 e agosto de 2002, financiado pela CAPES, participei de um estágio pós-doutoral na Universidad de Alcalá, na cidade de Alcalá de Henares, na Espanha, sob a supervisão da Profa. Dra. Ana María Cestero Mancera. Na sala dos becários, vi um folheto da Editora Ariel Linguística, anunciando uma publicação recente de Antonio Briz: El español coloquial en La conversación. Tal obra interessou-me bastante, pois à época dedicava-me aos estudos do português falado. Depois de conhecer a obra, busquei conhecer, também, o autor.

Depois de entrar em contato via correio eletrônico, agendei uma visita à Universitat de Valencia, pois tinha interesse em conhecer o pesquisador que tanto contribuía para os estudos da conversação, mais especificamente para os estudos da modalidade falada. Dessa forma, marquei um encontro e, quando entrei na sala do Prof. Briz, ocorria uma reunião do Grupo Val.Es.Co. Para surpresa minha, o coordenador do Grupo Val.Es.Co convidou-me a entrar e a participar da reunião. Dessa maneira, conheci, pessoalmente, o Prof. Antonio Briz e sua equipe.

Ao conhecer melhor os objetivos, metodologia e corpus do Projeto Val.Es.Co., percebi uma série de semelhanças com o Projeto NURC, do qual já fazia parte. Com isso, foi possível estreitar os laços acadêmicos e científicos. O Prof. Briz foi várias vezes à Universidade de São Paulo para ministrar cursos, contatos com doutorandos e trocas científicas entre Val.Es.Co. e NURC.

Por meio de um convênio entre a Universitat de Valencia e Universidade de São Paulo e graças ao apoio financeiro da CAPES, tive a oportunidade de realizar estâncias de pós-doutorado em Valência. Dessa forma, um simples objetivo comum - conhecer novas metodologias de estudo de língua falada - redundou em uma parceria bastante profícua, da qual docentes e alunos de doutorado foram envolvidos.

Considerando que o que me levou a conhecer o Prof. Antonio Briz foram os estudos sobre Análise da Conversação, para homenageá-lo, nada melhor do que trazer à luz um dos temas estudados à época: sobreposição de vozes no diálogo, postulando algumas razões determinantes da sobreposição por parte do interactante que não está com a palavra.

Para tanto, utilizei três inquéritos do Projeto NURC, do tipo D2, isto é, diálogo entre dois informantes, mais precisamente os inquéritos 255, 343 e 396., constantes em Castilho e Preti (1987).

\section{SOBREPOSIÇÃO DE VOZES NO DIÁLOGO}

Desde a segunda metade do século $X X$, os estudos sobre interação verbal têm sido objeto de estudo não só de linguistas mas também de sociólogos, antropólogos, psicólogos e educadores em geral. Esses estudiosos têm procurado entender os mecanismos que regem os mais diferentes tipos de conversação praticados na sociedade moderna. Esse interesse está relacionado ao fato de a conversação ser uma prática rotineira na vida dos seres humanos e também elemento vital para a comunicação. As conversações naturais não apresentam uma simples sucessão de 
intervenções de interlocutores; apresentam, sim, estruturas organizadas e sistemáticas, como bem demonstra o Prof. Briz em diversos estudos, em especial Briz Gómez (1995, 1996 e 1998).

Nas conversações espontâneas entre duas pessoas, há dois papéis conversacionais básicos: falante e ouvinte. Eles, indistintamente, estão ocupados em falar e escutar, por isso revezam-se nesses papéis sem que haja necessidade de acordo prévio. Há mecanismos conversacionais que sinalizam ao falante que seu interlocutor está acompanhando, entendendo e participando do tópico em desenvolvimento. Somente quando um interlocutor interrompe sistematicamente a palavra, o falante percebe a violação das regras conversacionais.

A dinâmica conversacional reflete a cooperação que há entre falante e ouvinte. $O$ interlocutor que detém a palavra recebe, sem abandonar o turno, determinados sinais que representam uma espécie de canal de retorno. Esses sinais são muito importantes, pois possibilitam ao falante controlar a qualidade da comunicação. Mediante essas expressões, aparentemente sem importância, o ouvinte pode proporcionar uma constante demonstração de apropriada escuta e participação.

Em geral, em um diálogo espontâneo, há alternância dos papéis conversacionais de falante e ouvinte. Vázquez Veiga (2003:106) esclarece que se pode considerar atividades de falante e atividades de ouvinte, contudo "não se pode estabelecer uma equação entre, por um lado, ser falante e ouvinte, e, por outro, ter o turno e não ter o turno. Sendo assim a afirmação que só fala quem tem o turno precisa ser revista." Ingve (1970) faz diferença entre ter o turno e ter a palavra. Dessa forma, é possível ter o turno e não ter a palavra, isto é, as breves intervenções de um ouvinte com formas do tipo uhn, uhn uhn, certo constituem turno, mas não indicam que o interactante que as emite tenha a palavra nem que deseje ter a palavra.

Nos diálogos espontâneos, os interlocutores se alternam e, quanto maior for o envolvimento dos interactantes, mais dinâmico e complexo será o fenômeno conversacional. Sacks, Schegloff e Jefferson, no clássico trabalho de 1974, referem-se a um princípio básico: "fala um de cada vez". Ainda que seja um princípio fundamental e imprescindível para o bom êxito da conversação, nem sempre é respeitado, mas é bom que se diga que as pessoas se entendem, mesmo falando ao mesmo tempo.

Sabemos que também é um fenômeno cultural. Na cultura brasileira, quanto maior envolvimento houver entre os participantes em um diálogo, mais ocorrências haverá de sobreposições de vozes. Por exemplo, em uma roda de conversa espontânea entre quatro ou cinco amigos, certamente, a regra "fala um de cada vez" será transgredida constantemente, sem que nenhum dos interactantes pense que aquele que interrompeu foi mal educado ou não conhece as boas regras da conversação.

Schegloff (1973:45) propõe um conceito de sobreposição que considera o momento em que as falas se sobrepõem: 


\begin{abstract}
exemplo, seu começo estiver próximo do que pode ser o ponto de completude do turno do falante anterior, então, referimo-nos a isso como sendo uma sobreposição. Se sua fala tiver sido projetada para começar no meio de um ponto que não é de nenhum modo um possível ponto de completude para o turno, então, referimo-nos a isso como sendo uma interrupção.
\end{abstract}

Como se pode deduzir da afirmação acima, a sobreposição ocorre, apenas, em posição final de turno do interactante que está com a palavra ou nos casos em que uma falsa projetabilidade do ouvinte o leva a confundir uma pausa mais longa e uma entonação descendente como sinais de fim de turno. Em outra situação, ocorre a interrupção. Em outras palavras, o citado autor faz diferença entre sobreposição de vozes e interrupção, ainda que, neste trabalho, não haja a preocupação em estabelecer qualquer diferença.

Cestero Mancera (2000:150) afirma:

\begin{abstract}
Toda interrupção sistematicamente, salvo em ocasiões casuais ou nas ocasiões em que se empregam estratégias diversas de tomada de palavra, a aparição do fenômeno que temos chamado de sobreposição. Podemos dizer, pois, que a sobreposição de voz está condicionada pela falta de atenção dos interactantes às indicações a respeito da conclusão da mensagem que se emite naquele dado momento. Nesse sentido, a sobreposição é um fenômeno condicionado, mas, por sua vez, trata-se de uma marca que caracteriza e sinaliza as alternâncias impróprias que se produzem na conversação.
\end{abstract}

Assim, percebe-se que, frequentemente, a sobreposição está relacionada à interrupção. É verdade, todavia é necessário não confundir os dois fenômenos e considerá-los como correlacionados, isto é, é preciso esclarecer que, nem sempre, a sobreposição de vozes, necessariamente, implica interrupção. São, portanto, fenômenos distintos.

Para efeitos deste trabalho, considero a sobreposição de vozes um fenômeno mais abrangente e uma categoria formal que ocorre quando duas falas ocorrem ao mesmo tempo, isto é, quando dois interactantes atuam simultaneamente, com ou sem intenção de interromper. Mais ainda, focalizarei a atuação do interactante que sobrepõe, postulando algumas razões determinantes que levam à sobreposição.

Foi feito um levantamento estatísticos nos três inquéritos trabalhados. O Inquérito 255 apresenta 82 minutos de gravação e contém diálogo entre diretor e professor de uma escola. Trata-se de um diálogo mais formal e tenso, pois, claramente, a variável hierarquia social interfere, sendo que, das 6 ocorrências de sobreposição de vozes, todas são efetuadas pelo diretor, que detém um status social mais elevado que seu interlocutor.

O Inquérito 343, com 80 minutos de gravação, apresenta diálogo entre dois irmãos, ele com 27 anos de idade e ela, com 25 anos. Trata-se de um diálogo bastante espontâneo, com 116 ocorrências de sobreposição de vozes.

Com 75 minutos de gravação, o Inquérito 396 apresenta diálogo entre dois irmãos, da terceira faixa etária (Ele com 67 e ela com 65 anos de idade). Este inquérito apresenta 150 ocorrências de sobreposição de vozes.

Para marcar os fragmentos dos diversos exemplos apresentados, seguiu-se um padrão: nome do projeto (NURC/SP), número do inquérito e página em que se encontra o fragmento do corpus, constante em Castilho e Preti (1987). 


\section{RAZÕES QUE LEVAM À SOBREPOSIÇÃO}

Foram considerados cinco motivos que levam um interactante a sobrepor sua fala à outra: concordância com o interlocutor, colaboração, reparo, falsa projetabilidade e manifestação de dúvida.

Em um diálogo, a participação dos interactantes é bastante dinâmica, sejam falantes, sejam ouvintes. Ao contrário do que se pensa, um ouvinte pode participar ativamente da interação, não só ouvindo, mas também interferindo na fala de seu interlocutor, seja para demonstrar atenção, entendimento, concordância, assentimento. Em outras palavras, o ouvinte monitora o falante, enquanto este está com a palavra. Trata-se do motivo mais comum das sobreposições de fala no diálogo.

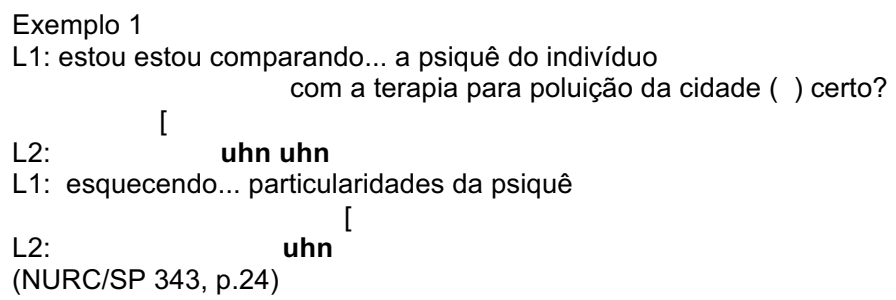

L2, interactante que não está com a palavra nem quer usurpá-la, deseja manifestar a seu interlocutor que está entendendo o que está sendo dito, por isso não há como esperar para alcançar seu objetivo; é preciso que se diga o que foi dito naquele instante, o que leva à sobreposição de vozes. Na segunda ocorrência, percebe-se que L2, depois da hesitação do interlocutor, sinaliza que L1 pode seguir adiante com o desenvolvimento do tópico.

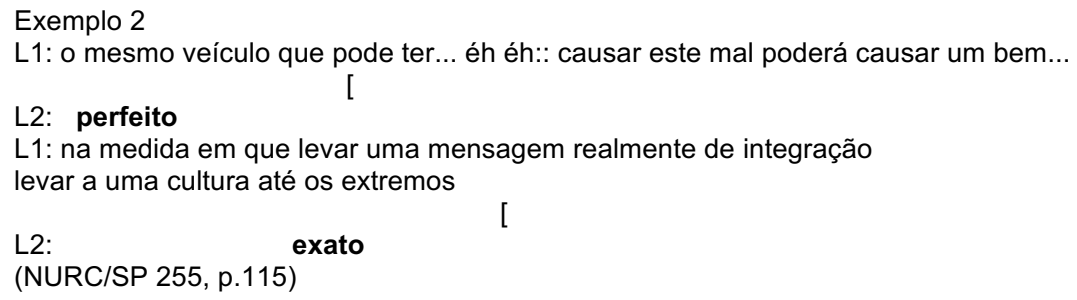

Nos dois casos do exemplo anterior, nota-se que o ouvinte não deseja tomar o turno de seu interlocutor; as intervenções deste servem para demonstrar que ele está de acordo com o que está sendo desenvolvido e sinaliza que o interlocutor pode seguir adiante no desenvolvimento do tópico. Nestes tipos de ocorrências, fica evidente que não se trata de falta de educação do interlocutor ao emitir um enunciado concomitante com o parceiro conversacional, pelo contrário, trata-se de elementos que deixam claro ao falante que o ouvinte está atento e prestando atenção ao que está sendo enunciado.

Preti (1988) pesquisou o problema da colaboração que denominou "sintaxe a dois". Tal fenômeno corresponde ao que Castilho (1989) chama de "sintaxe vertical". Trata-se de enunciados breves, produzidos pelo ouvinte, com a finalidade de completar algum enunciado de que o falante não se lembra. Pode ocorrer, também, uma antecipação de um possível enunciado do falante, isto é, o ouvinte, no ímpeto de participar do segmento 
enunciado pelo interlocutor, antecipa o que seria dito pelo interlocutor. Nem sempre, porém, a colaboração do ouvinte coincide com o enunciado do falante.

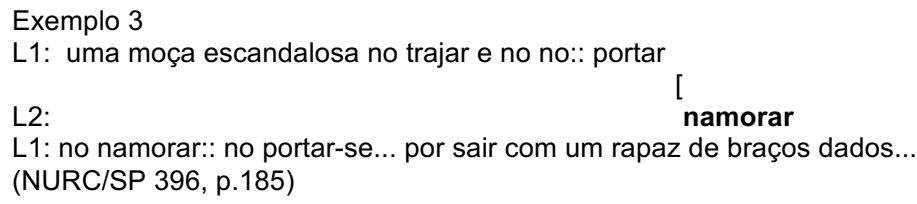

Percebe-se, neste caso, que L1 hesita ao completar um enunciado, com isso L2, demonstrando estar atento ao que está sendo explanado, procura ajudar o interlocutor e, em sobreposição de voz, emite o possível elemento buscado pelo falante. Repare-se que o falante sanciona positivamente a participação de $\mathrm{L} 2$, repetindo o enunciado "no namorar::".

Como a conversação é dinâmica, muitas vezes, o ouvinte não pode esperar que o falante finalize sua participação para intervir, especialmente, quando o ouvinte discorda do que o falante diz, fazendo algum tipo de correção ou reparo.

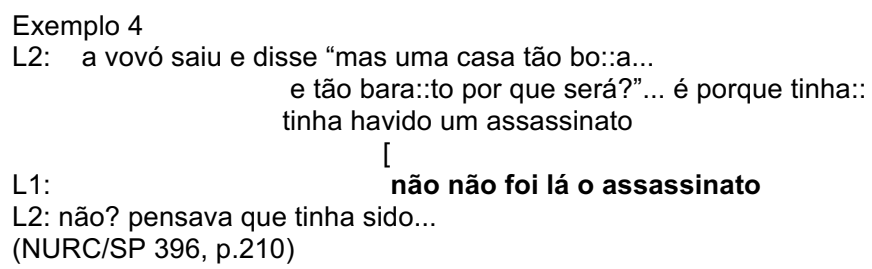

L2 contava que a avó havia comprado uma boa casa por um preço barato e dá a entender que o baixo preço se deveu ao fato de ter havido na casa um assassinato. L1, que é irmão de L2 e também conhece a história não concorda com o que diz o interlocutor, fazendo um reparo na história contada pelo falante. É importante que se diga que não era possível esperar que L2 finalizasse seu relato, caso contrário o equívoco se prolongaria. Como um alto grau de envolvimento entre os interlocutores, é possível fazer o reparo no momento do equívoco, o que leva L2 a ficar surpreso: "não? pensava que tinha sido...".

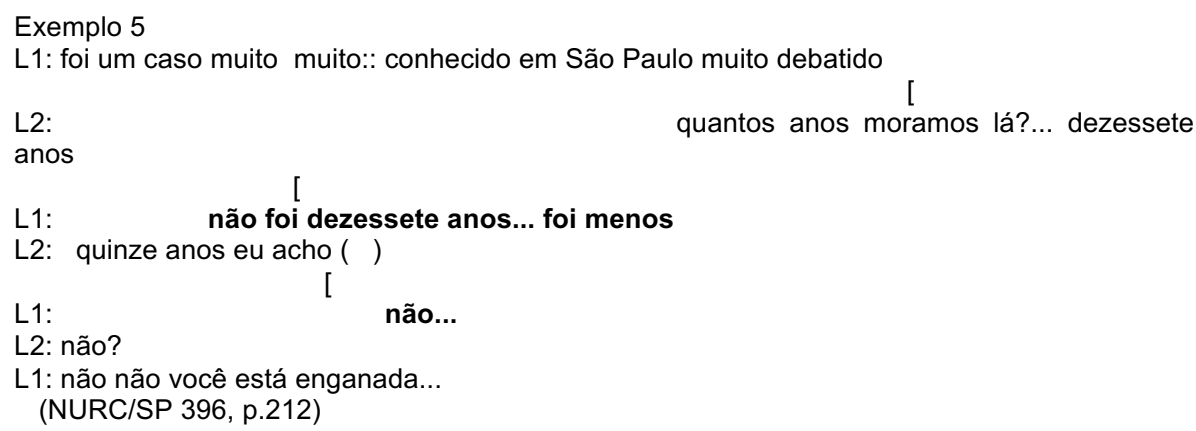

Nas duas ocorrências de reparo, feito em sobreposição de voz, é possível perceber que L1 interfere para reparar o enunciado de L2, deixando claro que as duas intervenções de L2 estavam equivocadas. L2 fica surpresa ao saber que está errada ("não?") e L1 não deixa dúvida a respeito: "não não você está enganada". 
Quando se desenvolve o texto conversacional, é comum utilizar-se da pergunta retórica para o desenvolvimento do tópico. Trata-se de uma pergunta que não é para ser respondida a não ser por quem faz a pergunta. Frequentemente, o interlocutor não entende que não é para responder e acaba respondendo, causando sobreposição de voz, pois o falante não esperava que o ouvinte respondesse. A esses casos, denomino falsa projetabilidade do ouvinte.

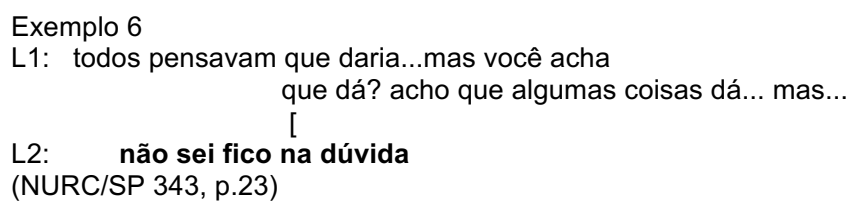

Percebe-se que L1 emite uma pergunta retórica, pois, sem que haja nenhuma pausa ou outro tipo de sinal, o falante começa a responder à pergunta feita por ele mesmo: "acho que algumas coisas dá...". O ouvinte L2, de imediato, busca responder, ainda que não esteja seguro de sua resposta: "não sei fico na dúvida".

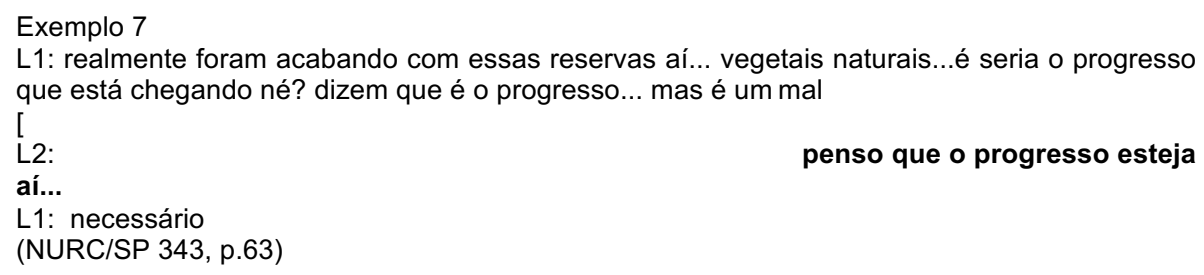

Neste exemplo, depois de sinais claros de que o falante havia terminado o turno (marcador né?, completude sintático-semântica), o ouvinte L2 projeta mal a sua participação, pois, na verdade, L1 não havia terminado completamente o segmento projetado.

Frequentemente, dinamicidade da conversação leva o ouvinte a interpelar o falante a respeito de alguma dúvida que, eventualmente, surja. Esse é o caso da manifestação de dúvida.

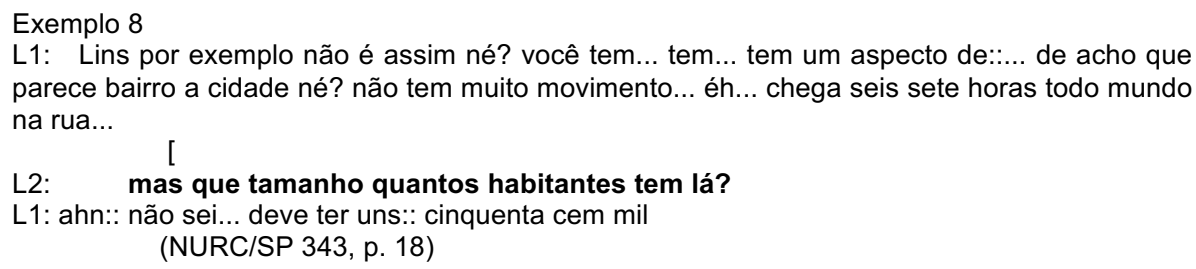

Em geral, nos diálogos, as sobreposições são breves e um dos interlocutores deve ceder a vez, a fim de que não haja ruído na comunicação. No exemplo acima, percebese que nenhum dos dois interlocutores cede a vez, no entanto a comunicação entre eles não apresenta qualquer problema. L1 falava a respeito da cidade de Lins e, naquele exato momento, L2 intervém, causando sobreposição de voz, com a finalidade de satisfazer a curiosidade a respeito do número de habitantes dessa cidade. É importante observar que é um dos raros exemplos em que os dois interlocutores completam a fala, sem que haja qualquer dificuldade de entendimento. Também, deve-se ressaltar que era fundamental que L2 interviesse naquele exato momento. 


\section{CONSIDERAÇÕES FINAIS}

A conversação é um dos eventos mais importantes da vida cotidiana, pois, por meio dela, entramos em contato com outras pessoas para nos comunicarmos. Na conversação, geralmente o tópico é desenvolvido por, pelo menos, duas pessoas, o que não significa que o texto conversacional apresente divisão estanque de papéis. Há, por isso, alternância dos papéis de falante e ouvinte: ora desempenha a função de falante, ora a função de ouvinte.

O mecanismo que governa a distribuição desses papéis é a tomada de turnos. Tal sistema é localmente comandado, isto é, vai se construindo aos poucos e o planejamento se dá no momento mesmo de sua realização. Dessa forma, o texto conversacional tem um caráter contextual e não automatizado. Sendo assim, é preciso observar em cada momento o que fazem os participantes. Caso o foco seja, unicamente, no falante, aquele que está com a palavra, teremos uma visão parcial dos fatos. Do mesmo modo ocorrerá se o foco estiver, unicamente, no ouvinte. É necessário, pois, realizar uma análise que integre as ações do falante e do ouvinte.

Neste trabalho, buscou-se focalizar a interação entre falante e ouvinte e, especialmente, os momentos em que se dá a violação da regra geral da conversação, "fala um de cada vez". O foco deste trabalho foi o fenômeno da sobreposição de vozes e, como foi esclarecido, não houve qualquer preocupação em definir e analisar a sobreposição do ponto de vista das estratégias de gestão de turnos, isto é, se houve ou não interrupção ou assalto ao turno, mas tão somente algumas razões que levam o interlocutor a sobrepor-se à fala daquele que está com a palavra.

Foram relacionados cinco motivos que levam o interlocutor a sobrepor-se ao falante: concordância com o interlocutor, colaboração, reparo, falsa projetabilidade $e$ manifestação de dúvida. Dessa relação, o primeiro é o mais frequente nos três inquéritos estudados. De qualquer forma, mais importante do que fazer um levantamento estatístico, é concluir que quanto maior for o envolvimento entre os participantes do diálogo, maior incidência haverá de sobreposição de vozes. Pelo mesmo no que tange ao português do Brasil, o fenômeno da sobreposição não é um sinal claro de má educação, pelo contrário, sinaliza o envolvimento interacional intenso, próprio das conversações espontâneas.

\section{REFERÊNCIAS BIBLIOGRÁFICAS}

Briz Gómez, Antonio (1995) (Coord.): La conversación coloquial (materiales para su estúdio). Valencia: Universitat de València.

Briz Gómez, Antonio (1996): El español coloquial: situación y uso. Madrid: Arco/Libros.

Briz Gómez, Antonio (1998): El español coloquial en La conversación. Esbozo de pragmagramática. Barcelona: Ariel.

Castilho, Ataliba T. de e Dino Preti (Orgs.) (1987): A linguagem falada culta na cidade de São Paulo. Vol. II, Diálogos entre dois informantes. São Paulo, TAQueiroz/Fapesp.
Cestero Mancera, Ana María (2000): El intercambio de turnos de habla en La conversación: análisis sociolinguístico. Alcalá de Henares: Universidad de Alcalá.

Ingve, Victor H. (1970): "On Getting a Word in Edgewise”. In M.A. Campbell ET al. (Eds.). Papers from the Sixth Regional Meeting. ChicagoLinguistic Society, 567-578. Chicago: Departement of Linguistics, University of Chicago.

Sacks, H.; Schegloff, E. \& Jefferson, Gail (1974): "A simplest systematics for the organization of 
Revisitando um velho tema: sobreposição de vozes no diálogo | L.A. da Silva

turn-taking for conversation". Language, 50:696-735.

Schegloff, E. e Sacks, Harvey (1973): "Opening up closing". Semiotica, 7.4:289-327.
Vázquez Veiga, Nancy (2003): Marcadores discursivos de recepción. Santiago de Costela: Universidade de Santiago de Compostela. 